\title{
Evaluation of Access to Public Water Supply in Two Major Cities in Nigeria
}

\author{
A. A. Amori ${ }^{1}$, A. A. Makinde ${ }^{2, *}$ \\ ${ }^{1}$ Water Resources Management and A grometeorlogy Department, University of Agriculture, Abeokuta, Nigeria \\ ${ }^{2}$ Farming Sy stem and Extension Department, National Horticultural Research Institute, Ibadan, Nigeria
}

\begin{abstract}
The issue of access to portable public water supply in the last three decades has been a topical issue of high interest to several individuals, communities, organizations and governments. In the face of dwindling and depleting water resources, there is the general concern of how people will have unhindered access to portable water supply. This paper against this background examined differences in public perception of access to portable water supply on the basis of some socio-economic and demographic factors such as gender, socio-economic background and marital status. The findings showed that there was a significant difference in public perception based on gender while there were no differences on the basis of marital status and socio-economic background. The implications of these findings for water resources management was discussed and recommendation made as to how access to public water supply can be easily guaranteed and sustained over time.
\end{abstract}

Keywords Socio-Economic Background, Accessibility, Portable Water, Serv ice Delivery, Water Supply

\section{Introduction}

Efforts at enhancing efficient public water supply is never complete until every citizen or inhabitants of a particular place have unhindered access to potable and safe water. The issue of access is very critical and essential as it becomes inefficient if public water is provided but does not get to the final users. This is sue becomes more pertinent if it is realized that most developing countries (particularly Africa) does not have efficient public water supply systems simply because its inhabitants do not have direct access to available water supply. This situation has made most development efforts in Africa difficult and complex as water is not available in required quantities to enhance the execution of major development tasks,[5],[6],[8]. Yet, water remains a commodity for which there is no substitute which has to be provided in order to ensure the execution of some essential human tasks. Given this scenario, it becomes critical to examine whether in the real sense, people have access to safe and portable water supply in Nigeria and how they perceive such access based on some socio-demographic factors such as gender, marital status and socio-economic background.

\subsection{Conceptual Clarification}

At this juncture, it becomes imperative to make some

* Corresponding author:

hakmak4u@yahoo.com (A. A. Makinde)

Published online at http://journal.sapub.org/ajee

Copyright (C) 2012 Scientific \& Academic Publishing. All Rights Reserved clarifications as it relates to the basic concept of this study. This is to ensure a thorough understanding and grasp of some is sues connected with this concept.

\subsection{Accessibility}

This refers to ease in getting to a place or obtaining a resource, good or service. This is often determined either by the distance it takes to get to a place or obtaining a good or service and the time taken. There are several dimensions to accessibility namely:physical, economic, social and political. The physical dimension has to do with the time and distance that separates the individual from the resource. The social dimension has to do with the level of interaction and class between individuals who do not have and those who have the resource or commodity in question. The economic dimension refers to the ability of an individual to afford and pay for a particular resource or good. This is largely affected by their income levels. The political dimension involves the individual's position with respect to bureaucratic set up and laid down procedures that guide the allocation of the good or resource[7][9]. For accessibility to be fully guaranteed these dimensions must be harmonized. That is, resources must be located well such that it will be available to satisfy the needs of those who need them.

\subsection{Access to Safe and Portable Water}

Access to safe and potable water supply based on the foregoing is enhanced by the ability to reach or obtain the service or facility (connection component) and the ease of obtaining water quickly and cheaply[1]. In spite of this, 
accessibility may not exist within these two levels at the same time as, it is possible to get to it but unable to obtain water due to social and financial constraints. Hence, access to potable water is only enhanced when it is readily available and every form of barrier in getting it is removed and it is sited close to the final users,[4] \& [3].

\subsection{State ment of Problem}

The study determined whether there were significant differences in the way respondents in Ibadan and Abeokuta perceive access to potable public water supply on the basis of some socio-demographic factors such as geographical location, gender, marital status and socio-economic background. The issue of access to portable public water supply has been a regular feature on a global scale in the last four to five decades. The issue becomes prominent and critical in sense that a lot of people all over the world do not have easy access to potable water supply in terms of economic, social and geographical (spatial) considerations. Water is crucial and critical to human survival and development. It is needed for both domestic, corporate, industrial and commercial uses. Where it is not available in required amounts and specific time, development becomes lopsided and stunted. Hence it is appropriate that people have access to water always at least for the purpose of development. Viewed against this back drop, this paper determined how residents of Ibadan and Abeokuta perceive the issue of access to potable public water supply and whether there are differences in their perceptions on the bas is of geographical location (that is, the study area), gender, marital status and socio-economic backg round..

\subsection{Research Question}

Do respondents differ in their perception of access to public water supply based on gender, marital status, socio-economic background and location (study areas)?

\section{Methodology}

\subsection{Sample and Sampling Procedure}

The study involved 400 respondents (consisting of 233 males and 167 females) spread over the two cities. The respondents were selected using stratified random sampling on the basis of local governments and wards, in the two cities.

\subsection{Instrument}

The major instrument used in the study for the purpose of obtaining information from respondents was a questionnaire titled "Questionnaire on the perception and assessment of access to portable public water supply. It consists of three sections. Section A covered issues relating to the personal background information of respondents such as age, sex, occupation, marital status, educational and socio-economic background and family structure. Section B dwelt on the evaluation of the nature of access sot public water supply while section $\mathrm{C}$ covers respondents perception of access to public water supply. Before final administration on respondents, the instrument was tested for reliability and it yielded a cronbach alpha value of 0.723 .

\subsection{Procedure}

The data collection exercise was undertaken by the researchers with the assistance of four trained research assistants. Questionnaires were administered on the respondents and retrieved immediately after they had been filled. It lasted six weeks.

\subsection{Data Analysis}

Analysis of the data collected involved the comparism of the mean of responses from the respondents using the t-test statistic for independent samples. The significance level was set at 0.05 . Analysis was computed with the Statistical Packages for the Social Sciences (SPSS) software version 15.0 for windows.

\section{Results}

The t-test statistic was used in analyzing the data since the variables under study, that is, gender, socio-economic background, marital status and geographical location/study areas exists in two groups. The results are presented in table 1 to 4

Table 1. T-test Comparison of the Mean Perception of Respondents on the Basis of Gender

\begin{tabular}{|c|c|c|c|c|c|c|}
\hline Gender & Sample $(\mathrm{N})$ & Mean & Standard deviation & T.cal & T.cri/obs & P.value \\
\hline Male & 233 & 1.3313 & 0.46484 & & & \\
\hline Female & 167 & 1.2096 & 0.40823 & 2.314 & 1.96 & $\begin{array}{c}0.021 \\
* \text { sig }\end{array}$ \\
\hline
\end{tabular}

*Significant at 0.05 as $\mathrm{P}<0.05$

Table 2. T-test Comparison of the Mean Perception of Respondents on the Basis of Marital Stat us

\begin{tabular}{|c|c|c|c|c|c|c|}
\hline Marital status & Sample (N) & Mean & Standard deviation & T.cal & T.cri/obs & P.value \\
\hline Single & 192 & 1.2708 & 0.44555 & & & \\
\hline Married & 208 & 1.2962 & 0.44463 & 0.036 & 1.96 & 0.971 \\
$* \mathrm{~ns}$
\end{tabular}

*not significant at 0.05 as $\mathrm{p}>0.05$ 
Table 3. T-test Comparison of the Mean Perception of Respondents on the Basis of Socio-Economic Background

\begin{tabular}{|c|c|c|c|c|c|c|}
\hline Gender & Sample $(\mathrm{N})$ & Mean & Standard deviation & T.cal & T.cri/obs & P.value \\
\hline Low & 186 & 1.2366 & 0.42612 & & & \\
\hline High & 214 & 1.2991 & 0.45892 & 1.404 & 1.96 & $\begin{array}{c}0.161 \\
* \text { ns }\end{array}$ \\
\hline
\end{tabular}

*not significant at 0.05 as $\mathrm{p}>0.05$

Table 4. T-test Comparison of the Mean Perception of Respondents on the Basis of Geographical Location (Study Areas)

\begin{tabular}{|c|c|c|c|c|c|c|}
\hline Location & Sample (N) & Mean & Standard deviation & T.cal & T.cri/obs & P.value \\
\hline Abeokuta & 182 & 1.2300 & 0.42189 & & & \\
\hline Ibadan & 218 & 1.3100 & 0.46365 & 1.805 & 1.96 & $\begin{array}{c}0.072 \\
* \mathrm{~ns}\end{array}$ \\
\hline
\end{tabular}

*not significant at 0.05 as $\mathrm{p}>0.05$

From table 1, it is evident that respondents vary and indeed are different in their perception of access to potable public water supply on the basis of gender because the $t$ value obtained or calculated (2.314) is greater than the $t$ value observed from the statistical table, that is 1.96 . Furthermore, the $\mathrm{p}$ value of 0.021 obtained is less than 0.05 and is therefore significant at $5 \%$ confidence level. Hence it can be safely concluded that there exist differences in the perception of access to access to public water supply by respondents based on gender as the male respondents do not view it the same way as the female respondents.

Table 2 shows that respondents do not differ in their perception of access to potable public water on the basis of marital status because the $t$ value obtained (0.036) is less than the t-value observed from the statistical table, that is 1.96. By the same token, the $\mathrm{p}$ value of 0.971 obtained is greater than the significance level set at 0.05 . In other words, it can be said that respondents whether single or married do not differ in their view or perception about access to potable public water supply as they view it the same way.

Table 3 also shows that respondents do not differ in their perception to access of potable public water supply on the basis of socio-economic background. This so, because the t-value obtained (1.404) is less than the t-value obtained from the table while the value of 0.161 obtained is greater than the significance level set at 0.05. In simple terms, one can infer that respondents whether rich or poor do not differ in their view or perception about access to potable public water as their view seem to be the same.

Table 4 clearly reveals that there is no significant difference in the perception of respondents about access to public water supply on the basis of geographical locations, that is, the study areas. Ibadan and Abeokuta. The t-value calculated (1.805) is less than the t value observed form the statistical table which is 1.96 . Furthermore, the $\mathrm{p}$ value of 0.072 obtained is greater than 0.05 and is therefore insignificant at 5\% confidence level. Hence, it can be safely concluded that there exists no difference in the perception of access to public water supply respondents on the bas is of the study areas, Ibadan and Abeokuta. This means that respondents in Ibadan perceive access to public water supply in the same way as those in Abeokuta.

\section{Discussion}

Access to potable and safe public water as mentioned earlier is a topical issue and has been that which had attracted a lot of attention, especially at international level. Water is essential resource that does not have a substitute. For this reason it, must be available at affordable cost to all irrespective of their socio-economic background. The results in the previous section showed that there were significant differences in the perception of respondents on access to safe public water supply on the basis of gender and not on the basis of marital status, socio-economic background and geographical location. This implies that whether married or single, rich or poor, regardless of their location in the study areas chosen, respondents view access to public water supply the same way. It is not surprising that this result came up because respondents are not agreed that they have unhindered access to water supply. This was so because many of them acknowledge in the course of the study that even though they are connected to water supply, yet they do not experience regular supply of potable water supply due to the long distance separating them from public taps or disconnection from public source due to inability to pay water levies or poor distribution system on which water supply is based. The implication of this experience is that a lot still needs to be done to enhance easy access to public water supply. This can only be made possible where water is made available at affordable cost and within the reach of every consumer, that is, the utility must cover as many people as possible. Easy access is guaranteed when users cover leas distance to obtain water with several people being served equitably. By so doing water is made available on a regular basis, in sufficient quantities, at affordable cost, in high quality and safe for the consumption of the users. This can be best achieved with the aid of a broad-based water policy, functional water supply system, a conducive environment for the coordination of water based activities and the institution of an arrangement that will encourage public-private partnership in water supply. 


\section{Conclusions}

This study investigated whether there are significant differences in the way public perceive access to safe and portable water supply on the basis of socio-demographic factors such as gender, marital status, socio-economic background and geographical location. Result revealed that there were no significant differences in the way public view the issue of access to safe and potable water supply. This is because many are not agreed on it when view against what obtains in reality in their various localities. Many are of the view that access to public water supply is greatly hindered by large distance to water points, high cost production coupled with regular increase in water levies charged. The implications of this were highlighted and recommendations made on how to ensure easy access to safe water supply by all.

\section{REFERENCES}

[1] Amori,A.A. (2001). Application of Cartography and GIS in Educational Planning in N.O. Ukocha and G.N. Nsofor (eds) Cartography and FIS in Nation Building. Lagos: Nigerian Cartographic Association 231 - 244.

[2] Amori, A.A. (2009). Water Resources Mapping in Nigeria: Fundamental Issues, Benefits and Constraints. Water
Resources 18, 18-25.

[3] Brookshire, D.S. and D. Whittington (1993). Water Resources Issues in Developing Counties. Water Resources Research. 29(7), 1883-1888.

[4] Clasen, T.F. and A. Bastable (2003). Faecal Contamination of Drinking Water During Collection. Collection and Household Storage. The Need to Extend Protection to the Point of Use. Journal of Water And Health, 1(3), 109-115.

[5] Faniran, A. (1987). Institutional Arrangements for the Planning and Management of Water Supply in Nigeria in Wunderlich, J. Egbert and A.A Balkoma (ed) Water for the Future: Rotterdam/Boston,317-333.

[6] Faniran, A. (1991). Water Resources Development in Nigeria. University Lecture Series. Ibadan: Ibadan University Press 95 Pps.

[7] Filani, M.O. (1987). Accessibility and Urban Poverty in Nigeria: In P.K. Makinwa and O.A. Ozo (eds). The Urban Poor in Nigeria. Ibad an Evans Publishers, 128-138.

[8] Handidu, J.A (1990). National Growth, Water Demand and Supply Strategies in Nigeria in the 1960's. Water Resources 1(1) 1-7.

[9] Ikporukpo, C.O. ( 1987). An Analy sis of the Accessibility of Public Facilities in Nigeria. Socio-Economic Planning Science, 21 (1), 36-47. 